\title{
The contribution of human psychology to disaster management: mitigation, advance preparedness, response and recovery
}

\author{
C. Percy ${ }^{1}$, Y. F. Chen ${ }^{2}$, A. Bibi ${ }^{1}$, D. Coles-Jordan ${ }^{1}$, E. Dodson ${ }^{1}$, \\ T. Evans ${ }^{1}$, D. Klingberg ${ }^{1}$ \& M. van der Bruggen ${ }^{1}$ \\ ${ }^{1}$ Psychology Department, Coventry University, UK \\ ${ }^{2}$ Department of Geography, Environment and Disaster Management, \\ Coventry University, $U K$
}

\begin{abstract}
This integrative review highlights the potential contribution of human psychology to disaster management, in terms of mitigation, advance preparedness, acute responses to events, and longer term psychosocial effects. The aim is not to conduct a detailed systematic review of the evidence in any one area, but rather to plot out a broad overview of the areas where work has been done, and highlight gaps where there is potential for further development.

Keywords: psychology, disaster, mitigation, prevention, preparedness, response, recovery, theory, intervention, behaviour.
\end{abstract}

\section{Introduction}

It has become convention to consider four distinct stages, i.e. mitigation, preparedness, response and recovery [1]. By the mitigation and prevention phase we refer to activities or perceptions relating to reducing the risks of disasters occurring, for example, to assess of reduce the risk of flooding, or to prevent chemical incidents. By the preparedness phase we mean considering, rehearsing and preparing what to do in the event of a disaster, for example, by conducting drills, exercises, and simulations. The response phase refers to activities and experiences of tackling immediate danger when a disaster occurs, for example, conducting search and rescue, or treating acute physical and psychological trauma. The recovery phase refers to activities and experiences associated with 
longer term relief once immediate risk to life has passed, for example, attending to food supplies and clean water, restoring infrastructure, or recovering dead bodies. Although these disaster phases are not necessarily clearly demarcated, and they constitute phases in an ongoing cycle rather than a linear process, they are a useful way to organise any consideration of the role that psychological theory or research might play. For the purpose of this review, the terms psychology and psychological are defined broadly as pertaining to human thoughts, feelings or behaviours relevant to/during any phase of disaster.

\subsection{Preparedness}

Perhaps the most researched or theorised disaster phase, from the perspective of psychology, is that of preparedness. There is a large and growing body of literature in this field, which falls into two broad categories: psychological aspects of disaster preparedness in general, and preparedness for the psychological impact of disasters in particular.

There have been numerous studies investigating the meaning and subjective perceptions of preparedness for different groups individuals and groups. These studies serve an important role in identifying concerns and areas where further training in preparedness is felt to be required. These have included, for example, nurses, physicians, medical students, and emergency department directors, particularly in relation to disasters associated with bioterrorism, weapons of mass destruction, and severe acute respiratory syndrome [2-12].

A smaller number of studies have investigated perceptions of preparedness in members of the general population, including homeowners and residents in relation to terrorist attacks, and animal owners/caretakers in relation to extreme weather events [13-16]. Some studies have recognised that particular groups of people may have distinctive concerns in relation to preparedness, for example, immigrant people, chronically ill patients and elderly people in conditions of assisted living [17-19]. Studies investigating perceptions of disaster preparedness are typically descriptive, and often based on self reports. Some authors have suggested that this means of collecting data can lead to somewhat distorted picture of who needs more preparedness training [20]. An interest has now emerged in developing psychometrically valid and reliable tools to assess preparedness [21]. Although measuring subjective perceptions of preparedness is an important step towards enhancing it, it does not necessarily tell us how individuals and groups are likely to behave in the event of an emergency. A number of studies have attempted to address this by asking people about their intentions. These have investigated the stated intentions and willingness of lay volunteers, active and retired nurses, and other healthcare workers to respond in a range of disasters, including bird flu epidemic, bioterrorism and disasters in general [22-26].

Some studies have taken the further step of attempting to predict the differential behaviour of individuals and groups, based on various personal factors and attitudes [27]. For example, examining relation ships between perceived response efficacy or fear of infection, and healthcare workers' willingness to carry out their roles $[28,29]$. Such studies may be used to not only 
predict, but potentially prevent or reduce levels of healthcare worker absenteeism in the event of a disaster [30, 31].

Moving from predicting to altering disaster behaviour brings us to a range of studies that have proposed or evaluated various interventions, drills, practices, or new technologies to enhance preparedness. The chief focus of these interventions is typically frontline response workers, including for example, nurses, emergency medical staff, medical students, nursing students, and fire-fighters $[32,33]$. Simulations are an increasingly popular means of offering training to these key groups $[34,35]$. New technologies are also a popular way to offer training and support for preparedness $[36,37]$. There is still debate as to the best means to evaluate the effectiveness of simulations and other training exercises $[38,39]$. An argument has been made that all frontline health professionals should receive disaster preparedness training, as part of the standard curriculum [40]. This would suggest that basic level of knowledge and skills is required for all professionals who are likely to encounter disaster situations. An alternative or adjunctive approach is to actively select for individuals who may possess knowledge, aptitudes or personal qualities that better suit them to leadership in disaster susceptible environments [41].

An area where there has been relatively little work published is that of developing and applying psychological theory to disaster preparedness. To achieve this requires more than describing or measuring individuals' and groups' perceptions or intended behaviours. Theory development entails developing models of the relationships between a range of variables, and crucially testing the models' ability to predict or modify behaviour. Rather few studies have taken a sufficiently broad perspective to identify the wide range of factors that may predict behaviour in disasters, perhaps because of the difficulties in obtaining data from such a wide range of actors and settings. Detailed and in depth reflections on disaster events are essential to developing theory that helps to explain not just what happened, but why. Good examples of this type of work include two detailed studies on institutional and community responses to hurricanes $[42,43]$.

Further refinement in the use of theoretical concepts is required to translate descriptive studies and simulations into altered disaster behaviour, for example distinguishing between the concept of disaster preparedness and disaster readiness [44]. The discipline of psychology is well placed to provide disaster researchers with well tested concepts that differentiate the broad category of perceptions/beliefs, into a more precise range of terms that include attitudes, cognitions, beliefs, subjective norms, self-efficacy, perceived behavioural control and so on $[45,46]$. Very few studies have applied well developed psychological models to predicting or modifying disaster preparedness behaviours.

While the majority of studies on preparedness relate to general responses, mental health specialists are increasingly aware of the needs to prepare in advance for the specific psychological impact of disasters. Suggestions have included preparing frontline workers such as public health staff, or counselling teams to administer psychological first aid or critical incident support [47-49], and developing a mental health preparedness toolkit [50]. It has also been argued 
that mental health care systems should strategically involve social community support and outreach, so that links are already well established and can readily be scaled up to respond in the event of a disaster [51]. This approach may be especially valuable when the scale of disaster is so great that responding is beyond the capacity of specialist mental health professionals. As this is particularly likely to be these case in developing countries and in large scale natural disasters, it has also been suggested that developing simple psychosocial interventions should be prepared in advance to enable vulnerable communities to provide their own response [52].

A considerable effort has been expended on making plans for terrorist attacks (including the use of bioterrorism) and cyclones, hurricanes, storms and tornados. Perhaps because of the actual or anticipated impact of these on North America in recent years. Rather less work has been done on preparedness for other events, such as factory, gas pipe or oil installation explosions, ice or snow storms, and power cuts. Given the large scale of the oil spill in the Gulf of Mexico in 2010, the possibility that climate change may produce more extreme weather events and energy crises lead to more interruptions of power, these areas of research may grow in future, or need to receive more attention.

\subsection{Mitigation and prevention}

Relatively little work has been done to apply psychological theory and research to the mitigation and prevention phase of disasters. Clearly this is particularly relevant in the case of technological and anthropogenic disasters, where human behaviour may be a key contributing factor in events. Ergonomic, industrial and organisational psychology have potential to explain and perhaps mitigate risky or erroneous human behaviours that may precipitate disasters [53]. Increasingly, it is recognised that such crises are rarely the product of one individual's actions alone. Some authors now take a systems approach to explaining anthropogenic disasters, such as the Ladbroke grove rail disaster in the UK [54]. Research on the contribution of human behaviour to the risk of disasters has been extended beyond the level of isolated incidents, to include broader risk phenomena. For example, some work has been done on residents' and disaster survivors' willingness to take mitigation measures against the risk of floods [55] and landslides [56]. Community psychologists have argued that understanding the psychological impacts of climate change may enable us to prevent it, by modifying community and global behaviour [57]. Some authors have argued that more needs to be done to investigate why powerful individuals and groups don't act to prevent anthropogenic environmental disasters [58]. Others have recommended that we develop psychological tools to discourage 'runaway' projects that may increase risk of disaster [59].

\subsection{Response}

Relatively little research has been done on the response phase of the disaster cycle, perhaps because of the difficulties of collecting data at a time when saving life, limb and essential infrastructure are of greater priority. While disasters may 
be inevitable, they are inherently unpredictable, so planning and implementing highly structured and complex research study designs may be out of the question. For that reason, most studies in this domain rely on retrospective accounts from those involved in the response phase of the cycle, albeit collected as near in time as possible to the actual events. Examples include experiences of people involved in providing psychological first aid after disasters in India, to rescue workers after the 2001 terrorist attacks in New York, to fire-fighters involved in responding to a landslide, and to those who worked on the rescue associated with Estonia ferry disaster [60-64]. That there are numerous examples of such work is probably a consequence of the emphasis that mental health professionals place on learning from reflective practice.

Perhaps more controversial is the practice of collecting first hand accounts from those more directly involved as survivors or rescuers, who may have been exposed directly to scenes of death, physical injury or personal physical risk. Critical incident debriefing was for many years assumed to be beneficial following trauma exposure, and had even become standard practice in some settings. However, following a number of systematic reviews that suggested that it may actually have adverse psychosocial effects, it is now considered best practice to screen for and treat only those who have manifest psychological disturbance following disasters [65-67]. Key considerations in understanding this debate are how debriefing is defined, and the extent to which individuals volunteer for or are encouraged to undertake it. The range of ways in which debriefing may defined is broad, and may include, for example, brief, single session, individual or group discussion, extended repeated and in depth examination of concerns, or vivid reliving of traumatic events. It has been suggested that pressuring individuals to participate in such activities may be deleterious to mental health, even when the intention is benign. A lack of clarity in the debate may lead some to conclude that it is probably best to leave exposed individuals to deal with direct or vicarious trauma in their own way, unless they actively seek psychological intervention, or exhibit clear symptoms of psychological disturbance. This has not, however, precluded researchers collecting data on experiences of disaster responders, for the purpose of research rather than therapy. Studies have been conducted on the subjective experiences of nurses following earthquake, rescue workers after terrorist attacks, train crashes and freeway collapse [68-71]. While participating in these accounts may or may not have psychological benefit or detriment for survivors and responders, they certainly have value in informing us about the nature of human experience on the response phase. Providing ethical concerns can be fully addressed, it may be worth making use of relatively unstructured qualitative and inductive designs to collect more data on these experiences. The use of novel technologies such as internet blogs may offer a means to collect contemporaneous data, where the infrastructure is available.

\subsection{Recovery and longer term psychosocial effects}

There have been a great many studies on the longer term psychosocial effects of exposure to disasters, corresponding the phase of disaster typically referred to as 
recovery. Most work has been done on the impact of disasters on survivors [7275]. Some work has begun to differentiate the special needs of particular populations, for example children [76-78]. However, relatively little work has considered the longer term psychosocial impact of disasters on women [79, 80], and on pre-existing chronic illness or disability.

There is also a growing recognition of the deleterious effects of vicarious trauma, for example on emergency services and military personnel [81-84]. Some research to date has recognised longer term psychological damage in people exposed to potentially traumatic situations, focusing on the prevalence and treatment of conditions such as Post Traumatic Stress Disorder (PTSD) [69, $72,83,85-87]$. PTSD is increasingly recognised as a common and debilitating mental disorder, and considerable effort has been expended developing and researching treatments for those affected [88-94]. However, what is not fully understood is why and how PTSD occurs in some people but not in others. The literature to date has tended to focus on studying individuals who are very distressed and have sought therapeutic intervention. This has arguably led to a pathologisation of human responses to trauma. A number of authors have pointed out that developing symptoms of PTSD is the minority response to traumatic events, and that most people so exposed display remarkably little psychopathology. It is suggested then that resilience is the more common response to trauma, and, just as there are individual differences in vulnerability to PTSD, there may also be numerous routes to resilience [95-100]. These pathways may be mediated by a combination of personal, psychological and social or contextual factors [101-103]. For example, psychological factors that have been linked to resilient response to potentially traumatic events include personality, optimism, extraversion, openness to experience, conscientiousness, low neuroticism, altruism, affect regulation, ego defences, controlled coping, learned helpfulness, effective behaviours despite fear, positive emotions, e.g. gratitude, love $[101,102,104-106]$. Social and contextual factors including bonding, teamwork, pre-existing relationships, social institutions, and organisational patterns and roles may also have a protective or buffering effect [101, 102, 104-106].

\section{Conclusions}

Few studies or interventions have applied psychological theory to disaster and related behaviours, despite the existence of numerous well established theories which have been used to predicting and modify behaviours in other contexts, such as health. There is scope for more application of psychological theory to the mitigation and prevention phases, at both a macro and micro level.

Studies assessing disaster preparedness often rely on self reports of subjective perceptions. More work is needed to test the predictive validity of perceptions and intentions, and to develop valid and reliable measures of disaster preparedness. There is still debate as to the best means to evaluate the effectiveness of simulations and other training exercises. More research is 
needed to identify the most valid and reliable means to evaluate preparedness interventions.

There is a need for more work on psychological aspects of the response phase, notwithstanding controversy about critical incident debriefing. This work could rely more on inductive qualitative designs and use novel data collection techniques. Psychological first aid doesn't necessarily have to be wholly reactive and/or provided by specialist professionals. If community members are integrated into existing healthcare systems, they may be trained to offer simple but effective support. Work needs to continue on identifying factors that promote resilience, and psychosocial interventions need to promote these factors to enhance resilience.

\section{References}

[1] Mileti, D., Disasters by Design: A Reassessment of Natural Hazards in the United States. Washington, DC: Joseph Henry Press, 1999.

[2] Rebmann, T. \& L.B. Mohr, Missouri nurses' bioterrorism preparedness. Biosecurity and Bioterrorism, 6(3): pp. 243-251, 2008.

[3] Rebmann, T., Defining bioterrorism preparedness for nurses: Concept analysis. Journal of Advanced Nursing, 54(5): pp. 623-632, 2006.

[4] Fung, O.W.M., A.Y. Loke, \& C.K.Y. Lai, Disaster preparedness among Hong Kong nurses. Journal of Advanced Nursing, 62(6): pp. 698-703, 2008.

[5] Silber, S.H., et al., Y2K medical disaster preparedness in New York City: confidence of emergency department directors in their ability to respond. Prehospital and disaster medicine: the official journal of the National Association of EMS Physicians and the World Association for Emergency and Disaster Medicine in association with the Acute Care Foundation, 16(2): pp. 88-94, 2001.

[6] Secor-Turner, M. \& C. O'Boyle, Nurses and emergency disasters: What is known. American Journal of Infection Control, 34(7): pp. 414-420, 2006.

[7] Jacobson, H.E., et al., Self-assessed emergency readiness and training needs of nurses in rural Texas. Public Health Nursing, 27(1): pp. 41-48, 2010 .

[8] O'Sullivan, T.L., et al., Disaster and emergency management: Canadian nurses' perceptions of preparedness on hospital front lines. Prehospital and disaster medicine: the official journal of the National Association of EMS Physicians and the World Association for Emergency and Disaster Medicine in association with the Acute Care Foundation, 23(3), 2008.

[9] Kollek, D., M. Welsford, \& K. Wanger, Canadian operational and emotional prehospital readiness for a tactical violence event. Prehospital and disaster medicine: the official journal of the National Association of EMS Physicians and the World Association for Emergency and Disaster Medicine in association with the Acute Care Foundation, 25(2): pp. 164169, 2010. 
[10] Alexander, G.C. \& M.K. Wynia, Ready and willing? Physicians' sense of preparedness for bioterrorism. Health Affairs, 22(5): pp. 189-197, 2003.

[11] Kaiser, H.E., et al., Perspectives of future physicians on disaster medicine and public health preparedness: Challenges of building a capable and sustainable auxiliary medical workforce. Disaster Medicine and Public Health Preparedness, 3(4): pp. 210-216, 2009.

[12] Becker, S.M. \& S.A. Middleton, Improving hospital preparedness for radiological terrorism: Perspectives from emergency department physicians and nurses. Disaster Medicine and Public Health Preparedness,. 2(3): pp. 174-184, 2008.

[13] Diekman, S.T., et al., Qualitative study of homeowners' emergency preparedness: experiences, perceptions, and practices. Prehospital and disaster medicine: the official journal of the National Association of EMS Physicians and the World Association for Emergency and Disaster Medicine in association with the Acute Care Foundation, 22(6): pp. 494501, 2007.

[14] Boscarino, J.A., C.R. Figley, \& R.E. Adams, Fear of Terrorism in New York after the September 11 Terrorist Attacks: Implications for Emergency Mental Health and Preparedness. International Journal of Emergency Mental Health, 5(4): pp. 199-209, 2003.

[15] Goodwin Jr, B.S. \& J.C. Donaho, Tropical storm and hurricane recovery and preparedness strategies. ILAR journal / National Research Council, Institute of Laboratory Animal Resources, 51(2): pp. 104-119, 2010.

[16] McConnico, R.S., Flood Injury in Horses. Veterinary Clinics of North America - Equine Practice, 23(1): pp. 1-17, 2007.

[17] Mori, K., et al., Health Needs of Patients With Chronic Diseases Who Lived Through the Great Hanshin Earthquake. Disaster Management and Response, 5(1): pp. 8-13, 2007.

[18] Carter-Pokras, O., et al., Emergency preparedness: Knowledge and perceptions of Latin American immigrants. Journal Of Health Care For The Poor And Underserved, 18(2): pp. 465-481, 2007.

[19] Feret, B. \& J. Bratberg, Pharmacist-based intervention to prepare residents of assisted-living facilities for emergencies. Journal of the American Pharmacists Association: Japan, 48(6): pp. 780-783, 2008.

[20] Kerby, D.S., et al., Self-assessment in the measurement of public health workforce preparedness for bioterrorism or other public health disasters. Public Health Reports, 120(2): pp. 186-191, 2005.

[21] Al Khalaileh, M.A.A., et al., The Disaster Preparedness Evaluation Tool(C): Psychometric testing of the Classical Arabic version. Journal Of Advanced Nursing, 66(3): pp. 664-672, 2010.

[22] Lau, J.T.F., et al., Perceptions related to human avian influenza and their associations with anticipated psychological and behavioral responses at the onset of outbreak in the Hong Kong Chinese general population. American Journal of Infection Control, 35(1): pp. 38-49, 2007. 
[23] Grimes, D.E. \& E.P. Mendias, Nurses' intentions to respond to bioterrorism and other infectious disease emergencies. Nursing Outlook, 58(1): pp. 10-16, 2010.

[24] DeSimone, C.L., Response of public health workers to various emergencies. AAOHN journal: official journal of the American Association of Occupational Health Nurses, 57(1): pp. 17-23, 2009.

[25] Fothergill, A., et al., The volunteer potential of inactive nurses for disaster preparedness. Public Health Nursing, 22(5): pp. 414-421 2005.

[26] Fulmer, T., et al., Organization-based Incident Management: Developing a Disaster Volunteer Role on a University Campus. Disaster Management and Response, 5(3): pp. 74-81, 2007.

[27] Larsson, G. \& A. Enander, Preparing for disaster: Public attitudes and actions. Disaster Prevention and Management, 6(1): pp. 11-21, 1995.

[28] Mackler, N., W. Wilkerson, \& S. Cinti, Will First-Responders Show Up for Work During a Pandemic? Lessons From a Smallpox Vaccination Survey of Paramedics. Disaster Management and Response, 5(2): pp. 4548, 2007.

[29] Prateepko, T. \& V. Chongsuvivatwong, Patterns of perception toward influenza pandemic among the front-line responsible health personnel in southern Thailand: A Q methodology approach. BMC Public Health, 9, 2009.

[30] Garrett, A.L., Y.S. Park, \& I. Redlener, Mitigating absenteesim in hospital workers during a pandemic. Disaster Medicine and Public Health Preparedness, 3(SUPPL.2), 2009.

[31] Damery, S., et al., Will the NHS continue to function in an influenza pandemic? a survey of healthcare workers in the West Midlands, UK. BMC Public Health, 9, 2009.

[32] Morrison, A.M. \& A.M. Catanzaro, High-fidelity simulation and emergency preparedness. Public Health Nursing, 27(2): pp. 164-173, 2010 .

[33] Beaton, R.D. \& L.C. Johnson, Instrument development and evaluation of domestic preparedness training for first responders. Prehospital and disaster medicine: the official journal of the National Association of EMS Physicians and the World Association for Emergency and Disaster Medicine in association with the Acute Care Foundation, 17(3): pp. 119125, 2002.

[34] Franc-Law, J.M., et al., The effectiveness of training with an emergency department simulator on medical student performance in a simulated disaster. CJEM : Canadian Journal Of Emergency Medical Care = JCMU : Journal Canadien De Soins Médicaux D'urgence, 12(1): pp. $27-$ $32,2010$.

[35] Lieberman, H.R., et al., Cognition during sustained operations: Comparison of a laboratory simulation to field studies. Aviation Space and Environmental Medicine, 77(9): pp. 929-935, 2006. 
[36] Chang, P., et al., The development of intelligent, triage-based, massgathering emergency medical service PDA support systems. The Journal Of Nursing Research : JNR, 12(3): pp. 227-236, 2004.

[37] Nyamathi, A.M., et al., Nurses' perceptions of content and delivery style of bioterrorism education. Journal for Nurses in Staff Development, 23(6): pp. 251-257, 2007.

[38] Paton, D., Disaster relief work: An assessment of training effectiveness. Journal Of Traumatic Stress, 7(2): pp. 275-288, 1994.

[39] Lee, Y.I., et al., Large emergency-response exercises: Qualitative characteristics - a Survey. Simulation and Gaming, 40(6): pp. 726-751, 2009.

[40] Parrish, A.R., et al., A short medical school course on responding to bioterrorism and other disasters. Academic Medicine, 80(9): pp. 820-823, 2005.

[41] Slaven, G. \& R. Flin, Selecting managers for a hazardous environment. Disaster Prevention and Management, 6(5): pp. 336-342, 1995.

[42] Seale, G.S., Emergency Preparedness as a Continuous Improvement Cycle: Perspectives From a Postacute Rehabilitation Facility. Rehabilitation Psychology, 55(3): pp. 247-254, 2010.

[43] Parker, C.F., et al., Preventable catastrophe? The Hurricane Katrina disaster revisited. Journal of Contingencies and Crisis Management, 17(4): pp. 206-220, 2009.

[44] Lusby Jr, L.G., Are you ready to execute your facility's emergency management plans? Journal Of Trauma Nursing : The Official Journal Of The Society Of Trauma Nurses. 13(2): pp. 74-77, 2006.

[45] Motoyoshi, T., K. Takao, \& S. Ikeda, Determinant factors of communitybased disaster preparedness: A case study of flood prone area. Shinrigaku Kenkyu, 75(1): pp. 72-77, 2004.

[46] Takao, K., et al., Factors determining residents' preparedness for floods in modern megalopolises: the case of the Tokai flood disaster in Japan. Journal of Risk Research, 7(7-8): pp. 775-787, 2004.

[47] Parker, C.L., et al., Establishing evidence-informed core intervention competencies in psychological first aid for public health personnel. International Journal Of Emergency Mental Health, 8(2): pp. 83-92, 2006.

[48] Parker, C.L., et al., Expanding disaster mental health response: A conceptual training framework for public health professionals. International Journal Of Emergency Mental Health, 8(2): pp. 101-109, 2006.

[49] Nightingale, A., G. Smith, \& D. Scott, Counselling and support services for civil emergencies and major incidents. Psychodynamic reflections. Psychiatric Bulletin, 21(8): pp. 486-488, 1997.

[50] Hoffman, Y., et al., Identification and evaluation of mental health and psychosocial preparedness resources from the Centers for Public Health Preparedness. Journal Of Public Health Management And Practice : JPHMP. Suppl, 2005. 
[51] Panyayong, B. \& W. Pengjuntr, Mental health and psychosocial aspects of disaster preparedness in Thailand. International Review of Psychiatry, 18(6): pp. 607-614, 2006.

[52] Sadeghi, N. \& M.H. Ahmadi, Mental health preparedness for natural disasters in Iran. Natural Hazards, 44(2): pp. 243-252, 2008.

[53] Reason, J., The contribution of latent human failures to the breakdown of complex systems. Philosophical transactions of the Royal Society of London.Series B: Biological sciences, 327(1241): pp. 475-484, 1990.

[54] Lawton, R. \& N.J. Ward, A systems analysis of the Ladbroke Grove rail crash. Accident Analysis and Prevention, 37(2): pp. 235-244, 2005

[55] Clark, D.E., et al., Willingness to pay for flood and ecological risk reduction in an urban watershed. pp. 235-242, 2002.

[56] Lin, S., D. Shaw, \& M.C. Ho, Why are flood and landslide victims less willing to take mitigation measures than the public? Natural Hazards, 44(2): pp. 305-314, 2008.

[57] Kagan, C., Working at the 'edge': Making use of psychological resources through collaboration. Psychologist, 20(4): pp. 224-227, 2007.

[58] Rodolfo, K.S. \& F.P. Siringan, Global sea-level rise is recognised, but flooding from anthropogenic land subsidence is ignored around northern Manila Bay, Philippines. Disasters, 30(1): pp. 118-139, 2006.

[59] Rafizadeh, H.A. \& B. Baker, Avoiding disaster through the "reconsideration trigger": Preventing runaway nuclear power projects. Journal of Asia-Pacific Business, 10(1): pp. 80-96, 2009.

[60] Rao, K., Lessons learnt in mental health and psychosocial care in India after disasters. International Review of Psychiatry, 18(6): pp. 547-552, 2006.

[61] Reeves, J.J., Perspectives on disaster mental health intervention from the USNS Comfort. Military Medicine, 167(9 SUPPL.): pp. 90-92 2002.

[62] Garcia, E. \& D.A. Horton, Supporting the Federal Emergency Management Agency Rescuers: A variation of critical incident stress management. Military Medicine, 168(2): pp. 87-90, 2003.

[63] Clifford, B., The New South Wales Fire Brigades' critical incident stress management response to the Thredbo Landslide. International Journal Of Emergency Mental Health, 1(2): pp. 127-133, 1999.

[64] Nurmi, L.A., The sinking of the Estonia: the effects of critical incident stress debriefing (CISD) on rescuers. International Journal Of Emergency Mental Health, 1(1): pp. 23-31, 1999.

[65] Rose, S., J. Bisson, \& S. Wessely, A systematic review of single-session psychological interventions ('debriefing') following trauma. Psychotherapy and Psychosomatics, 72(4): pp. 176-184, 2003.

[66] Everly Jr, G.S. \& J.T. Mitchell, The debriefing "controversy" and crisis intervention: a review of lexical and substantive issues. International Journal Of Emergency Mental Health, 2(4): pp. 211-225, 2000.

[67] Rose, S. \& J. Bisson, Brief early psychological interventions following trauma: A systematic review of the literature. Journal of Traumatic Stress, 11(4): pp. 697-710, 1998. 
[68] Shih, F.J., et al., Taiwanese nurses' most unforgettable rescue experiences in the disaster area after the 9-21 earthquake in Taiwan. International Journal Of Nursing Studies, 39(2): pp. 195-206, 2002.

[69] Bills, C.B., et al., Stories behind the symptoms: A qualitative analysis of the narratives of $9 / 11$ rescue and recovery workers. Psychiatric Quarterly, 80(3): pp. 173-189, 2009.

[70] Ben-Ezra, M., et al., Acute stress symptoms, dissociation, and depression among rescue personnel 24 hours after the Bet-Yehoshua train crash: the effects of exposure to dead bodies. Prehospital and disaster medicine: the official journal of the National Association of EMS Physicians and the World Association for Emergency and Disaster Medicine in association with the Acute Care Foundation, 23(5), 2008.

[71] Marmar, C.R., et al., Stress responses of emergency services personnel to the Loma Prieta earthquake Interstate 880 freeway collapse and control traumatic incidents. Journal Of Traumatic Stress, 9(1): pp. 63-85, 1996.

[72] Neria, Y., A. Nandi, \& S. Galea, Post-traumatic stress disorder following disasters: a systematic review. Psychological Medicine, 38(4): pp. 467480, 2008

[73] Neria, Y., et al., The mental health consequences of disaster-related loss: Findings from primary care one year after the 9/11 terrorist attacks. Psychiatry, 71(4): pp. 339-348, 2008.

[74] Tol, W.A., et al., Political violence and mental health: A multidisciplinary review of the literature on Nepal. Social Science and Medicine, 70(1): pp. 35-44, 2010.

[75] Tol, W.A., et al., Communal violence and child psychosocial well-being: Qualitative findings from Poso, Indonesia. Transcultural Psychiatry, 47(1): pp. 112-135, 2010.

[76] Kar, N., Psychological impact of disasters on children: Review of assessment and interventions. World Journal of Pediatrics, 5(1): pp. 5-11, 2009

[77] Stallard, P., Psychological interventions for post-traumatic reactions in children and young people: A review of randomised controlled trials. Clinical Psychology Review, 26(7): pp. 895-911, 2006.

[78] Davis, L. \& L.J. Siegel, Posttraumatic stress disorder in children and adolescents: a review and analysis. Clinical Child And Family Psychology Review, 3(3): pp. 135-154, 2000.

[79] Ross-Sheriff, F., Women and disasters: Reflections on the anniversary of Katrina and Rita. Affilia - Journal of Women and Social Work, 22(1): pp. 5-8, 2007.

[80] Rees, S., E. Pittaway, \& L. Bartolomei, Waves of violence - Women in post-tsunami Sri Lanka. Australasian Journal of Disaster and Trauma Studies, 2005(2): pp. 19-27, 2005.

[81] Gallagher, S. \& S. McGilloway, Living in critical times: The impact of critical incidents on frontline ambulance personnel: A qualitative perspective. International Journal Of Emergency Mental Health, 9(3): pp. 215-224, 2007. 
[82] Malek, M.D.A., A. Fahrudin, \& I.S.M. Kamil, Occupational stress and psychological well-being in emergency services. Asian Social Work and Policy Review, 3(3): pp. 143-154, 2009.

[83] Richardson, L.K., B.C. Frueh, \& R. Acierno, Prevalence estimates of combat-related post-traumatic stress disorder: Critical review. Australian and New Zealand Journal of Psychiatry, 44(1): pp. 4-19, 2010.

[84] Steel, Z., et al., Association of torture and other potentially traumatic events with mental health outcomes among populations exposed to mass conflict and displacement: A systematic review and meta-analysis. JAMA - Journal of the American Medical Association, 302(5): pp. 537-549, 2009.

[85] Attanayake, V., et al., Prevalence of mental disorders among children exposed to war: a systematic review of 7,920 children. Medicine, Conflict, And Survival, 25(1): pp. 4-19, 2009.

[86] Bills, C.B., et al., Mental health of workers and volunteers responding to events of 9/11: Review of the literature. Mount Sinai Journal of Medicine, 75(2): pp. 115-127, 2008.

[87] Johnson, H. \& A. Thompson, The development and maintenance of posttraumatic stress disorder (PTSD) in civilian adult survivors of war trauma and torture: A review. Clinical Psychology Review, 28(1): pp. 36-47, 2008 .

[88] Bisson, J.I., et al., Psychological treatments for chronic post-traumatic stress disorder - Systematic review and meta-analysis. British Journal of Psychiatry, 190: pp. 97-104, 2007.

[89] Bastien, D.L., Pharmacological treatment of combat-induced PTSD: A literature review. British Journal of Nursing, 19(5): pp. 318-321, 2010.

[90] Crumlish, N. \& K. O'Rourke, A systematic review of treatments for posttraumatic stress disorder among refugees and asylum-seekers. Journal of Nervous and Mental Disease, 198(4): pp. 237-251, 2010.

[91] Mevissen, L. \& A. de Jongh, PTSD and its treatment in people with intellectual disabilities. A review of the literature. Clinical Psychology Review, 30(3): pp. 308-316, 2010.

[92] Mevissen, L., R. Lievegoed, \& A. de Jongh, EMDR Treatment in People with Mild ID and PTSD: 4 Cases. Psychiatric Quarterly, pp. 1-15, 2010.

[93] Ponniah, K. \& S.D. Hollon, Empirically supported psychological treatments for adult acute stress disorder and posttraumatic stress disorder: A review. Depression and Anxiety, 26(12): pp. 1086-1109, 2009.

[94] Stewart, C.L. \& T.A. Wrobel, Evaluation of the efficacy of pharmacotherapy and psychotherapy in treatment of combat-related posttraumatic stress disorder: A meta-analytic review of outcome studies. Military Medicine, 174(5): pp. 460-469, 2009.

[95] Bonanno, G.A., et al., Psychological resilience after disaster: New York City in the aftermath of the September 11th terrorist attack. Psychological Science, 17(3): pp. 181-186, 2006. 
[96] Bonanno, G.A., Resilience in the face of potential trauma. Current Directions in Psychological Science, 14(3): pp. 135-138, 2005.

[97] Bonanno, G.A., C. Rennicke, \& S. Dekel, Self-enhancement among highexposure survivors of the september 11th terrorist attack: Resilience or social maladjustment? Journal of Personality and Social Psychology, 88(6): pp. 984-998, 2005.

[98] Bonanno, G.A., Loss, Trauma, and Human Resilience: Have We Underestimated the Human Capacity to Thrive after Extremely Aversive Events? American Psychologist, 59(1): pp. 20-28, 2004.

[99] Mancini, A.D. \& G.A. Bonanno, Resilience in the face of potential trauma: Clinical practices and illustrations. Journal of Clinical Psychology, 62(8): pp. 971-985, 2006.

[100] Yehuda, R., et al., Developing an agenda for translational studies of resilience and vulnerability following trauma exposure, in Psychobiology of Posttraumatic Stress Disorder: a Decade of Progress., Blackwell Publishing: Oxford. pp. 379-396, 2006.

[101] Agaibi, C.E. \& J.P. Wilson, Trauma, PTSD, and resilience: a review of the literature. Trauma, Violence \& Abuse, 6(3): pp. 195-216, 2005.

[102] Charney, D.S., Psychobiological Mechanism of Resilience and Vulnerability: Implications for Successful Adaptation to Extreme Stress. American Journal of Psychiatry, 161(2): pp. 195-216, 2004.

[103] Sandler, I., Quality and Ecology of Adversity as Common Mechanisms of Risk and Resilience. American Journal of Community Psychology, 29(1): pp. 19-55, 2001.

[104] Fredrickson, B.L., et al., What Good Are Positive Emotions in Crises? A Prospective Study of Resilience and Emotions Following the Terrorist attacks on the United States on September 11th, 2001. Journal of Personality and Social Psychology, 84(2): pp. 365-376, 2003.

[105] Ong, A.D., et al., Psychological resilience, positive emotions, and successful adaptation to stress in later life. Journal of Personality and Social Psychology, 91(4): pp. 730-749, 2006.

[106] Riolli, L., V. Savicki, \& A. Cepani, Resilience in the face of catastrophe: Optimism, personality, and coping in the Kosovo crisis. Journal of Applied Social Psychology, 32(8): pp. 1604-1627, 2002. 